SF 545

.C27

Copy 1

\title{
PRACTICAL METHOD
}

一)FOR THE(-

CUXTIVATION OF

MULBERRY TREES,

RAISING OF

SILK W0RIIS, COCO0NS, Ete.

BY

CARERA, HUBER \& CO.

$$
\text { N E W IV O R K. }
$$

A. Cariglianu, Printer, Publisher ei Translator. 280 MOTT STREET. 



\section{Practical Method}

-)FOR THE(-

\section{CULTIVATION OF}

\section{MULBERRY TREES,}

RAISING OF

\section{SILK WORIS, COCO0NS, Etc.}

B Y

CARERA, HUBER \& CO.

NE W Y R K.

A. Carigliano, Printer, Publisher $\&$ Translator. 280 MOTT STREET. 
Entered aceording to Act of Congress in the year $1803 \mathrm{by}$ Carera, Huber \& Co, in the Office of the Librurian of Comgress in Washington. 


\section{PREFACE.}

As many of our patrons have addressed letters to us, asking for information and advice, in regard to the culture of the mulberry tree and the care of the silk-worm, and knowing full well the inpossibility of answering all parties concerned individually, we have decided to compile the fresent pamphlet, wherein all the necessary information may be obtained.

And by so doing we flatter ourselves, that we will thus become useful to our patrons, in promoting the increase of this newly-started industry in this country, which we are assured, will, in a very short time, develop considerably, owing principally to climate, soil, and the intelligence and industry of the American people.

New York, Dec. r 883 .

The Authors,

CARERA HUBER \& CO.

${ }_{152}$ Wooster Street. 



\section{MULBERRY TREE CULTURE.}

\section{Its origin.}

The mulberry tree (morus) was discovered as an indigenons plant, in Bengal, India, and in the Chinese Empire. The importation of the black mulberry (morus nigra) into Europe is lost in the records of history; that of the white mulberry (morus alba) is of a more recent date-between the years $35^{\circ}$ and 400 of the Christian Era.

The mulberry tree requires a climate similar to that of a vine, and will perish at a temperature below ro degrees. This tree is not suited to that climate, where, afier itsleaves are gathered in spring, the mean temperature $i$, not, for three months at least 50 . At 65 degrees the leaves fully develop. In order that the tree may produce the requisite yuantity of leaves, it is necessary that, from the time in which it begins to-bud to that in which the temperature, after the heat of summer is lowered to 70 degrees, may receive at least 15,000 degrees cf heat. Every branch we may imagine to be divided into three parts, viz.; the interior, or hard wood, which feels entirely the heat of summer; the middle, or green wood, which grows during the last heat of summer, and the beginning of autumn; and the superior jart, or bark. Hence, in a temperate climate, during the blasts and colds of winter, only the bark, or the tip of the branch, will be affected. 


\section{How to select a Mulberry Tree}

In the manner of selecting mulberry trees, we do not choose those plants which are too big neither do we choose very large leaves, but those trees that grow gradual and regular, thus guaranteeing their tenacity and durability - a tree pleasing to the eyes, and profitable to the purse of the growers. We have also in view, in our selection of plants, to choose those best adapted to the different localities.

There are a great varieties of mulberry trees; but the grower must select those whose leaves are larger and most consistent; by thus doing accruing larger profits to himself by raising a better quality, and a larger quantity of cocoons. The principal species of mulberry trees are the black and white.

The black mulberry tree (morus nigra) was imported into Italy and Spain, from Greece and Sicily. Its fruit is black and sweet, and was eaten by people long before it was thought of using its leaves as food for the silk - worm. Its organization being robust, its bark thick and woody, its fibres close, its vegetation less precocious, all seem to be in harmony with a late spring in a cold climate, and clearly indicate, that, thougin the tree is an indigenous of warm climates, it can also thrive in colder ones. The silk - worm feeds well on its leaves, though the silk produced is not of a fi ce quality.

The white mulberry tree (norus alba) is of more recent importation, as previously stated, and is only suitable for warm climates. The silk - worm that feeds on its leaves produces a better quality of silk, By ingrafting the two 
species a new plant is reproduced suitable for any clime.

'There is also another kind of mulberry tree, that of the Philippine Islands called "morus cuculata or multicaule," on account of the many shoots that spring up from the base of the trunk. It was discovered by Perrotet and Matrilla, in those islands and introduced in Europe in 1821 , first in France, and afterwads in Italy. Its leaves are very large and easily torn by the wind. In structure is less consistent than the other two species, and its roots are easly preyed upon by squirrels. It is propagated by seed or ingrafting. The leaves being formed early in the season, the feeding of the silk-worms will become earlier.

'The principal varieties obtaint $d$ by the seed of the white mulberry tree are the following: the "Spagno-R(man, that of Tuscany, the Morettiano, rosea, Male Piranidales and ibridis."

\section{Propagation of the Mulberry Tree.}

The propagation of the mulberry tree is ordinarily accomplished by its seed. 'The plant must be vigorous and the seed gathered from branches two years old. But, as the mulberry is not a plant that bears hermophrodite flowers, but only the male and female, separated from each other, and often the female abounding, care should be taken, that on the same, or a neighloring plant, be found male flowers, otherwise the seed will not produce fruit.

The gathering of the fruits should be accomplished by shaking the tree, so as to collect only the ripe ones. 'The 
fruits are placed in a receptacle containing water, and are there mashed, to separate the seed from the pulp. 'The good seed being heavier, will fall to the bottom of the receptacle, and the bad ones will float. The water is then poured off leaving the good seed at the bottom. And in this manner of manipulation, only the good seeds will remain. They are then dried in an airy and shady place.

'To keep the seeds until spring, put them in dry sand, and keep in a place free from dampness and airy. The seed that is kept over a year will lose its strength. 'The best time to sow the seed is in June, but care should be taken to keep the seed always shaded from the rays of the sun. For this purpose straw or dry leaves are strewn on the earth over them.

The soil selected should be well worked and freed from weeds and small stones. More than manure a soft soil is needed. Divide your field into squares and in these squares cig four furrows, one foot apart, and about, $\mathrm{r} / 2 \mathrm{inch}$ (o, oz centm.) deep.

The seed should be put in the soil by scattering. Between the furrows another one is to be kept open, about one foot $(0,25$ centm. ) wide, for the workman to pass, and to allow the plant more scope to grow.

During the growth of the plant the soil should be kept constantly free from weeds and well-raked, - to keep-the ground open, and this must be done until the plant has at tained a height of about 8 inches ( 20 cent.)

After the shoots have sprung up, the proper distance of one from the other should be $1 / 2$ foot (ro centimtr.) All the others should be uprooted and planted at that distance. 


\section{$-9-$ \\ Planting.}

The soil best adapted for the mulberry tree must be of a calcareous and argillaceous nature, dry and deep, and not altogether devoid of organic matter.

Before the planting of the shoots, the soil should be worked to the depth of at least 2 feet, and it must be done before the winter sets in, so as to allow the earth to acquire the strength necessary for regetation.

In opening the furrows, the superficial strata should be kept apart from the lower one, and freed from all small stones and rubbish. The best time to open the furrows is in August.

Before planting the young shoots, care should be taken that all decayed portion; of their roots be carefully trimmed. The trunk should be cut about half a foot from the ground, to give vigor to the roots.

In setting out the shoots, keep the roots free and spread them out well; next take a small thin piece of wood, about the height of the shoot, to be used as a means oi support, and grasping them both with the left hand, fill in evenly the earth about the roots with the right,

The superficial earth should be placed upon the surface, leaving about the plant a small circular cavity sufficient to retain water to assist the vegetation.

Always bear in mind the fact, that the roots should not 3 buried too deep in the earth.

The first thing to be done after planting the shoots is to prune them at the height of 4 inches (rocentm.) from the sround, placing the cut-off portion of the shoot alongside 
the plant, so as to mark the spot. Next is to free the shoots with the hands or with a sharp instrument, of all buds, after the third week of their vegetation with the exception of the best and more vigorous one, which is generally found near the ground. Of this latter, the ntmost care should be taken.

In establishing a nursery the shoots are to be placed four feet (one meter) apart; but planting them for good the distance from trunk to trunk should be at least 16 to 24 feet (8 meters.)

When the shoots reaches to the height of one or two feet, buds spring forth from along its trunk. These should be let alone, as they are essential to the derelopment of the roots.

No matter how good the soil ma be, it is extremely difficult that the shoots reach in one year to the desirable height - not less than six and no more than eight feet. In that case pruning is necessary using all care, and exercising all attention to the young plant.

But if they develop well, leave them alone; only keep the soil free from weeds and rake it two or three times a year. If however, after a second pruning, the shoots do not develop as they should, the tree will be of an inferior quality.

When the shoots have arrived to the height of six or eight feet-which is generally in their second year-proceed to the formation of their branches. Only when the trunk of the shoots has acquired a circumference of from $4 \frac{3}{4}$ to 6 inches it is fit to be transplanted from the nursery, the holes for this purpose should be four feet deep by four feet wide and at least 16 to 24 feet distant from each other.

In spring the vertical branch must be cut. Only four 
or five well developed buds are kept on which the ingrafting is to be done on the following spring. Once the top (head) of the shot being well formed, no further care need be taken of it, except in pruning the superfuous branches.

If the wild mulberry produces large and good leaves, no ingrafting should be made.

The number of buds to be left on the shoot must be limited to the number of branches required.

\section{Ingrafting.}

If perchance the mulberry plant possesses large and abundant leares, and shows a well-developed growth, no ingrafting should take place, because instead of improving, it would deteriorate the species.

'To ingraft at the foot of the shoot is not advantageous in cold climates. In temperate climates it is most convenient in those parts exposed to the rays of the sun, and protected from the winds of the north; and the variety which is ingrafted must not be of the primitive white mulberry. In cold climates it is essentially necessary; for the branches of the wild mulberry make a better resistance to the colds of winter, and, it often happens, that if the ingrafted portion belongs to the white species, and the ingrafting is done at the foot of the tree, the tree itself will perish, while if done on the branches, even if bad, can always be made anew.

The most favorable time for ingrafting is, without doubt, in the spring, and a good season must be selected, 
that will promise many days of favorable weather. The month of May, and the beginning of June are the two months favorable for ingrafting mulberry trees. The ingrafting by bandages is preferrable to all other systems.

But ingrafting by sprigs can be performed indifferently either on small or large branches.

\section{The care of Grafted Trees.}

Until we are perfectly assured of the good success of the ingrafting at the foot of the tree in this cold American climate, it is necessary, to facilitate the development, to set the tree in a place well-protected-near a wall for instance, if possible-and exposed to the south, south-east, or southwest, and in a soil well - manured and well - worked.

These trees will begin to vegetate at the foot. Only the best sprig should be kept, the others destroyed; also. the old trunk, ahove the sprich, should be cut off.

The mulberry trees which are transplanted in autumn should be buried first in a ditch; not in bundles, but disposel one by one, in a position a little inclined - oblique - and left there until the propitious season to plant again arrives.

This earth-bath, given to the young plant, will impart to it vigor and new life. It must be borne in mind, however, that very little of the shoot should be left above ground.

The best ingrafting is obtained from the following species:

The low mulberry, "ceppaia" (block - like;) "spalliera" (Espalier;) and "castello" (castle-like.) 
The branches cut in winter, and placed in diry sand, in a cellar, are good for ingrafting wild mulberrys.

The pruning must be done in accordance with the age of the tree, its vigor, the nature of the so.l and climate. No leaves should begathered until after the sixth year of its growth; for if before that time, only $2 S$ or 30 llss. ( 4 or $15 \mathrm{ki}$ logr.) of leares will be gathered, while if not githered during these six years the tree will yield more than 40 lbs. (2o kilogr.) of leaves.

In sandy soil the ramification should be kept rather short. The pruning must be accomplished every two or three years, and never in summer.

'The mulberry tree is endowed with long life, even in cold climates. In its wild state it reaches the age of 300 and more years, but when ingrafted it loes not live so long-less than 100 years.

The reasons for this are the following:

ist. By ingrafting, the branches being more porous and less strong, are more liable to suffer by the inclemency of the weather and other causes.

2nd. By gathering the leaves every year, thus leaving the plant for ten or twelve days without respiratory organs, and the roots must necessarily suffer.

3rd. By badly executed pruning. To avoid this, it is always to be done longitudinally on the trunk of the tree, and on that side more exposed to the sun. (are should also be taken to remove the sap, which is not absorbed by the branches or leaves.

4th. By not working the ground properly, using the 
plow or spade carelessly, cutting off the superficial roots of the plant, which are essential to its well-being.

5th. By sowing near the mulberry tree any plant that spreads its roots too wide, thus extracting the greater yortion of the tree's nutriment.

6th. If the soil is not deepenough, and devoid of the qualities essential to the growth of the mulbery tree.

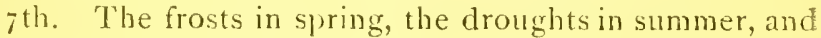
the excessive colds of winter, preceded by downpourings, and followed by a sudden rise in temperature, all combine to impede the growth and deteriorate the quality of the mulberry.

8th. And lastly, all that can affect a plant, as insects, squirrels, and many other small animals that feed on roots.

The quality and quantity of the crop varies according to chimate, the age of the tree, the soil, manner of pruning, etc., and wilt, most always, be affected by some of the above mentıoned causes.

The leaves of the wild mulberry are beiter food, in the beginning, for the silk-worms, being more dry. When the mulberry reachesa certain age, it must be shorn of many of its branches, to maintain exulibrium between branches and roots, and the plant in conseyuence will produce less leaves.

\section{Manure.}

Which will be the best manure for the mulberrys? As chemical analysis has shown us which is the best adapted 
soil for planting, so it will also guide us in selecting the best manure.

According to the analysis of the mineral matter contain ed in the leares and trunk of the mulberry, it is found that the trunk contains more lime, while the leaves more potash, phosphoric and azotic acids. So that the lest manure for this plant is that which furnishes lime, potash, phosphoric acid, and is not devoid of azotic substances, to develop, the leaves.

The best manure for yolng trees is from the decomposition of regetable matter.

And if this decomposition could take place in the ditcls where the shoot is to be planted so much the better. Decayed limbs of fruit - bearing trees or any regetalble matter placed in the ditch increase the strength of the shoot.

The effect of manure on the plant, being by emanation or absorption, the more the emanation or absorption, the letter will be the result. It is for this reason, that the mulberry, planted where manure is kept, thrives most vigorously, for there the organic and inorganic principles essential to its development are found.

Pronuction of the Mutrerky Tree provided the I,EAVES ARE NOT GATHERED BEFORE THE SIXTH YEAR.

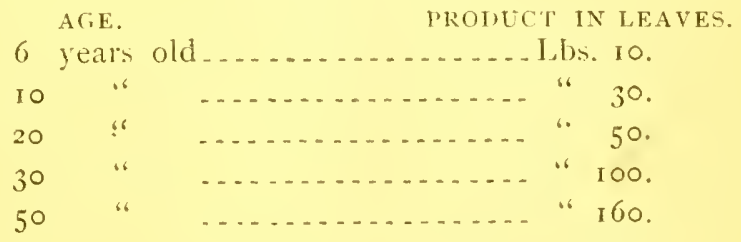




\title{
Brief Method for Silk-Worm Culture.
}

\author{
PRELIMINARY REMARK ABOUT SILK- \\ WORMS AND COCOONS.
}

The silk-worms belong to the numerous family of the "Bruchi." Their existence is classed into three periods ; larva chrysalis, and butterfly. However they are not perfect inseçts, and are incapable of reproducing their own species, except in their last period of existence, and feed only in the first.

During the first period, they change their skin frequently. In the other their skin changes only when passing from the chrysalis to the butterfly state.

It seems Nature has placed animated beings there, where food for their existence is abundantly provided. So the silk-worm is found to be indigenuus to Bengal and the Chinese Fmpire, as is also the mulberry tree, on whose branches it was first discovered.

The silk - worm belongs to the "Genus Bombyx", and to the species of the muberry, as its name in natural history, "Bombyx Mori," implies.

At present great varieties of silk-worms are known; some by the changing of their skin, during their first period of existence, and are called "mute;" some by hatching their eggs once, or several times, during the year, and are called "Bivoltini, Trivoltini, and Polivoltini," and some by the volume and color of the cocoons.

These varieties and species of silk-worms are known, and cultivated in Europe. 
The most diffused, and the most cultivated in Italy is that called the "Quattro Mute." or Four Changes, whose egges are not capable of deveionment except once a year, and whose cocoons are yellow, white, and green and of other rolors blending with all the alsove.

The life of these insects is divided into five eqrochs, which are called ages. The first four ages are readIy discerned by the insect changing its skin. Juring the fifth age the insect begins the spinning of the cocoon. The silk is derived from the cocoons, which are composed of very siender threads, varying in length from $1,+00$ to 1.600 feet ( 400 to 500 metres.)

The other two stages of life include only two periods. The first, that of the chrysalis, the second, that of the butterfly; and this last period continues until the two seres meet to reprodace their own species, by depositing their eggs.

In the stage of larva, the silk-worm breathes hy is little tubes, or tracheas (wind pipes,) which communicate with the exterior air, by as many little holes evenly divided on each side of its body near the feet.

The insect, larra, does not possess sexual organs.

Once the larva begins to feed, it remains immorable, until the moment arrives for the spinning of the rocoon. in the state of chrysalis it is apparently dead. Shut up in a cartilaginous vagina, within the cocoon, it possesses no cther movement but a lateral one, at the lower end of the lody, which shows the only sign of life.

As a butterfly it possesses a respiratory organic system. Only one trachea, eyes, sexual organs; and the female, ovaries. The male is possessed of an amorous disposition toward 
propagating the species, cohabiting for four days, if disturbed, he immediately seeks another female whom he approaches with pristine impetus.

The female is more home-like and modest though not less transported toward the propagating of its species. She lays between 300 and 400 eggs.

\section{Theoretical and Practical Principles for the Culture of Silk-Worms}

Nature is the best teacher. Hence, by following the teachings of Nature in the culture of the silk - worm the best results will be attained.

The cultivator should keep his silk-worms in an airy place, which must also be kept clean; taking away the old leaves, and providing the worms abundantly with new ones, fresh and good. The principal thing the cultivator should do, is to supply himself with an abundant stock of eggs, which must be laid by butterflies, and pronounced good after a microscopical examination.

\section{Preservation of Eggs.}

The eggs are to be kept in a room well-aired, and dry, and exposed, if possible, to the north. The temperature in winter must not be above 7 or 8 degrees Reaumur (about 
40 Fahr.) Frost is more cong enial to the eggs, than otherwise. But the changes of temperature are to be feared, especially from the beginning of February

\section{Incubation.}

About the time when the mulberry tree begins to bud the eggs acquire a temperature of 10 to in degrees Reaumur, (about 53 Fahr.) and incubation soon takes place when the temperature is increased to 12 or 13 degrees, about 55 Fahr. upwards, to 18 degrees Reaumur [about 65 Fahr.]

'This temperature is to be kejt constant and the air should be a little moist, to produce the opening of the eggs. It is most important to avoid a lowering of temperature, during incubation, if a good quality of silk-worms is to be desired.

\section{Nursing.}

1st. Age. As soon as the little silk-worms are born, they are to be gathered on a fresh, tender leaf of the mulberry. and thus placed on clean sheets of paper, observing that the silk-worms obtained from 10 grams of weight in eggs, when they reach at the end of this age, they must cover a superficial area of 9 square feet. They are to be kept as much as possible, to a temperature of 17 or 18 degrees Reaumur, (about 75 Fh.) and fed with well - chopped 
up leaves every two or three hours; that is, nine or twelve times in every 24 hours.

The day previous to the first change, that is, when the worm's head begins to enlarge, all the refuse leaves should be removed, and a very light feeding given toe the worms. Even when they are sick, keeping them to the same hours. as previously stated, in feeding, to prevent the suffering by hunger for those that have not reached such an advanced stage. But when many have reached this stage, then a suspension in the manner of feeding is necessary, to equalize their quality and growth; and in this way we must also act during the three other changes of skin.

Observing that as soon as the worn shows signs of life, from the state of torpor in which it lies, it can be kejt without food for 24 hours or longer, without any inconvenience.

'This furst age lasts six days, and, during this interval they consume about 7 pounds ( 3 kilogs.) of leaves.

2nd. Age. During this age they may be fed once upon the same bed on which they slept upon in the first age, and then transported by means of mulberry sprigs, to another place, where new, clean sheets of paper are spread; and, at the end of the age, must occupy a space of 18 square feet ( 2 metres square)

The temperature, feeding, and treatment, must be exactly the same as in the first age. The second age lasts four days, the worms consume about is pounds ( 7 kilogr.) of leaves.

3d. Age. During this age, which will last five days, the same treatment above stated must be followed, 
with this exception only: to place the worms upon a new or larger bed, so as to occupy a space 27 feet square $(3$ metres squale.) They will consume now about 42 pounds ( $20 \mathrm{kil}$.) of leaves.

4th. Age. By following these rules carefully, the worms, I 5 days from the time of their birth, will enter their fourth period. They must now occupy a space of about 65 square feet [ 7 metres sq.] They will reach this age in 7 days. The worms being now more vigorous, and better developed, the leaves may be given whole, and not chopped; and the feeding can be reduced to 6 times in every 24 hours. If the temperature should increase more than 17 degrees Reaumur, (about 75 Fahr.) windows and doors should be opened. If it should fall below i6 degrees Reaumur (about 65 Fahr.) a fire should be made. But good ventilation, and the same temperature should always be maintained. The worms will consume during this age, I 32 pounds ( 60 kilogr.) of leaves.

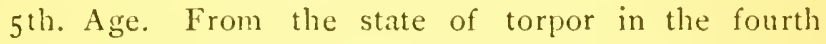
age, the worms awake to the fifth. They must now be distributed over a space double that of the fourth age about I $40 \mathrm{sq}$. ft. (I 5 metres sq.) During the eighth or ninth day at most, first, some few, and finally all, will begin to spin their cocoons, and crawl about on the dry stems of the leaves, which must be previously placed, broom-like, all along the feeding ground.

In this age they must be kept scrupulously clean, and, every day, their bed should be changed. The worms, in this last age, are excessively voracious: and for this reason plenty of leaves must be supplied to them. And if 
the feeding be not very frequent, it must be abundant. The leaves must be placed at least three inches deel\% especially during the last three days previnus to their departure for the grove.

In very warm weather, on sultry days, during storms and heavy rains, more ventilation is necessary, because both heavy and bad air is death to the worm. They consume during this age about 660 pounds ( 300 kilogr.) of leaves.

During the entire period of nursing, with eggs weighing only ten grams, worns will be produced consuming about 858 pounds ( 390 kilogr.) of leaves, and spinning cocoons weighing complexively about 55 pounds $(25$ kilogr.)

\section{The Grove.}

The silk-worms, nursed as previously stated, in 30 days from brith, will betake themselves to the grove. The grove is to be made up of branches of different species of shrubs. They must be perfectly clear from insects, clean, and dry. They are placed all along the tables on which the worms are kept, some even resting on the tables, branches downward so that the worms may crawl up easily.

The cultivator must now select those worms that are ripe, handling them lightly and with despatch. In this condition they are transparent, inclined to wiggle, keeping their heads constantly moving about, and looking for a support. This is to be done to help them. and to place 
them, if necessary on the branches; and for three days, the greatest care must be taken, as previously stated; for, during these days the worm wit begin spinning.

\section{Management of the Cocoonery after the Cocoons are spun.}

The windows and doors must be kept open day and night. After four days the worm will be enclosed in the rocoon, its transformation into chrysalis complete, and eight days after the cocoons can be collected, 420 of the latter if yellow in color and of good Milanese quality, will w eigh about $21 / 2$ pounds [ $\mathrm{r}$ kilogr.]

\section{Confection of the Silk-Worm Eggs.}

When the cocoons are gathered from the grove, artihicially built in the Cocoonery, select and keep for seed those that are harder more regular in shape, of an even color, and transparent as much as possible. Remove all the superfluous coating, or froth like sulsstance, to facilitate the egress of the butterfly from the cocoon.

In selecting the cocoons as seed, care should be had to choose always by pairs-male and female-which are easily distiguished by their shape. The male is enclosed in cocoons that are smaller more pointed at the extremities, and de- 
pressed at the sides. Those of the female are more rounded, fuller, and with less depression.

The butterflies make their exit from the cocoons on the 17 th or 18 th day after their introduction into the grove.

'The birth of the butterfly takes place between the hours of 4 and 9 A. M.

The males, whose bodies are pointed and small, will tlap their wings with violence: the females have a larger and longer body, and are not so active.

When the butterflies cohabit together, they should be placed upon another shelf and after six hours are separated by taking them by the wings and pulling them gently apart in opposite directions.

Then the female is placed alone on a piece of cotton fabric, and in 40 or 50 hours she will lay the eggs.

\section{Suffocation of the Crysalis.}

Any oven whatsoever can be used to suffocate the crysalis provided it be hot.

The cocoons are placed in the oven in baskets when the temperature is from 200 to 240 degrees and suspended from the floor of the oven at the height of at least i centimetre.

The cocoons are to be kept in the oven one hour at a temperature of 240 to 260 degrees of heat. After the lapse of 45 minutes, take from the midst of the basket some cocoons, cut them open, and ascertain about the complete suffocation of the crysalis. 
Before taking the basket of cocosns out, let the door of the oven open for about i 2 or 15 minutes to prevent any dampness.

\section{Cocoonery.}

Any room can be used for such a purpose, provided it be above ground, free from dampness, kept warm, and at least $100 \mathrm{sq}$. ft. ( 12 meters sq.) in dimension. There must be three windows to the east, south, and west, communicating to the door of the room, thus producing a good ventilation.

In this room, of whatever dimension it may he, a suitable stove is kept. The windows must be, as much as possible opposite to one another, and never towards the north.

The floor and ceiling of the room must be in perfect order, so that neither the air without can penetrate nor the heat within escape.

When the room has a dimension of from roo to r 80 sq. ft. (i 2 to 20 meters) it is necessary to have artificial ventilation, by means of a fan. When it has a dimension of 180 or more square feet ( 20 meters sq.) or upwards, what follows must be observed:

I. That the room have windows on two opposite sides.

2. That the windows be at least $r_{2}$ feet (3 meters) apart.

3. That the height of the windows be between 5 and 
$8 \mathrm{ft}$. (I, 50 meters or 2 meters) not taking into account their width.

4. That all along the ceiling and in the middle of the room be ventilators, that may be shut and opened at pleasure.

5. That there be in some part of the room a contrivance, to remove immediately the beds on which the silk-worms rested.

6. That all windows be towards the east or west, or towards the south-east or south-west.

7. Besides the outer door there should be an inner one to prevent a current of air or draft, which would be injurious to the silk-worms nearest it.

8. The window should have no clear glass, if there are no blinds.

9. And, if there are no blinds, paper, dipped in linseed oil. mixed with resin, is pasted on the window sash, answering the purpose, being transparent and strong enough to resist rain and wind.

10. Every window should have a green curtain, to keep off the rays of the sun.

I1. That there be a ventilator to change the air.

12. For every 200 to 250 square feet $(24$ or 28 meters sq.) of the room, a stove must be kept, with sufficient capacity to warm it. The height of the room should never be more than about 16 feet [4 meters.]

13. Finally, the room must be compact, so that it may soon be warmed, and kept so, with the most economical consumption of coal and wood. At the distance 
of every I 20 square feet [ 4 meters sq.] a thermometer must be suspended upon the wall distant from stoves, I 2 feet ( 3 meters,) and $4 \frac{1}{2}$ feet [1, o5 meters, ] from the floor.

The tables or shelves upon which the worms are nursed, may be of any wood whatever, provided they be white and smooth. They must be stationary, and made of thin wood for economy's sake.

Thy may be of any dimension, and the racks large enough to hold the worms of one ounce of eggs in weight, and are disposed in shelf-fashion for convenience. The distance between one shelf and the other must be about two feet (40 cent.) and must be perfectly steady. 


\section{P R I CE L I S T.}

Lombardian Mulberry Trees.

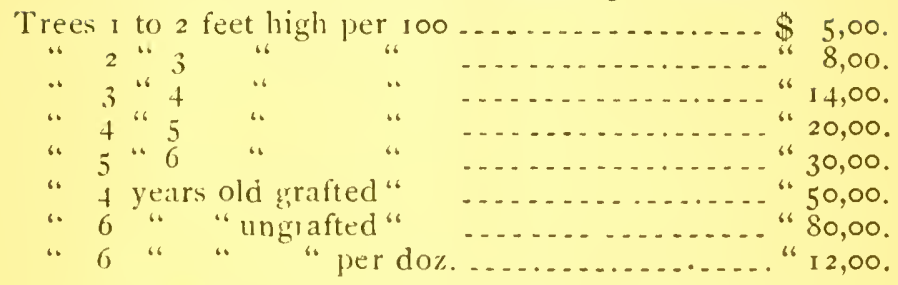

A LIBERAL DISCOUNT ON ORDERS OF IOOO OR MORE.

These trees are endowed with a very strong organization, which enables them to grow in cold comntries. The leaves are hardy and pulpy, so that the worms fed by them will produce large and heary cocoons.

\section{Silk - Worm Eggs.}

\section{BREEDING OF 188}

Silk worm eggs, confectioned by the cellular system, and examined by a physiological and microscopical selection ; free from disease, proceeding from a successful breeding of the previous year, in either white, yellow or green cocoons, $\$ 5,00$ per ounce of 25 grams.

Our agency will provide also Machinery for reeling cocoons.

All orders and informations promptly attended to.

Package and Freight from New York to destination to be paid by the consignee.

Orders must be accompained by cash (postal card or check or registered letter) and are guaranteed to be filled as soon as goods arrive in New York.

CARERA, HUBER \& CO.

I 53 Wooster St., NEw York. 



\section{INDEX.}

PAGE,

Preface,

Mulberry 'Tree's origin

How to select a Mulberry Tree _. . $\quad \ldots \ldots$. . . . 6

Propagation of the Mulberry Tree ... $\quad \ldots \ldots \ldots 7$

Planting

Ingrafting

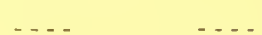

-... 9

Care of Grafted Trees

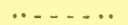

-... I I

Manure

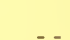

- - . I 2

Production of the Mulberry Tree... $\quad \therefore . . .$. I5

Remark about Silk-Worms and Cocoons ... . ... I6

Practical principles for the Culture of Silk-Worms _... I $\$$

Preservation of Eggs

_. . . I 8

Incubation

Nursing

The Grove

Management of the Cocoonery after the Cocoons arespun 23 Confection of the Silk-IVorm Eggs 


